\title{
Correlation of Uroflowmetry with Lower Urinary Tract Symptoms in Patients with Symptomatic Benign Prostatic Hyperplasia at Eastern Part of Nepal: A Prospective Study
}

\author{
Dr. Niraj Thapa ${ }^{1}$, Dr C.S. Agrawal ${ }^{2}$ \\ ( 1 \&2Department Of Surgery, Division Of Urology, B.P Koirala Institute Of Health Sciences , Nepal )
}

\begin{abstract}
:
Aims: To study the correlation between IPSS and uroflowmetry in patients with symptomatic benign prostatic hyperplasia

Material and methods: This is prospective study done from june 2015 to may 2016 in department of urosurgery BPKIHS, Dharan, Nepal. Total of 100 patients with symptomatic benign prostatic hyperplasia were included in the study. All patients lower urinary tract symptoms and their urofowmetry parameters were entered in preform profoma.

Conclusion: Of the 100 patients that presented with BPH, most of the patients (47.5\%) were in the age group of 60-69 years. It was found that prostate size had moderately positive correlation with LUTS while PVRU was found to have a weakly positive correlation with severity of urinary symptoms. Among the parameters which were obtained by uroflowmetry, Peak flow rate (Qmax) was found to be the most representative of the symptom severity of the patient. Average flow rate (Qavg) and voided volume showed no correlation with the symptoms of the patients. Through our study, we concluded that uroflowmetry is a valuable tool for the diagnosis of patients presenting with Lower Urinary Tract Symptoms. We can also assess the efficacy of our treatment by performing pre operative and post operative uroflowmetry.
\end{abstract}

Keywords: Benign prostatic hyperplasia, international prostate symptom score, post void urine, uroflowmetry.

\section{Introduction}

Benign Prostatic Hyperplasia (BPH) is a major cause of morbidity in the ageing men. ${ }^{1}$ It is the most common benign tumor in men with initial development usually after 40 years of age. By 60 years of age, its prevalence is greater than $50 \%$ and by age 85 is as high as $90 \%$. Of these, between $15 \%$ and $30 \%$ men have symptoms. ${ }^{2}$ In patients with BPH, enlargement of the prostate generally leads to bladder outlet obstruction (BOO) and it causes a variety of lower urinary tract symptoms (LUTS). ${ }^{3}$ However, the relationship between BPH and LUTS is complex because not all men with histological evidence of BPH will develop LUTS. Moreover, not all patients with BPH and LUTS will have prostate enlargement. ${ }^{4}$ The symptoms of BPH are classified as voiding and storage symptoms. The voiding symptoms include hesitancy, decrease in force and caliber of the urinary stream, intermittency, dribbling, and sense of incomplete evacuation. The storage symptoms are frequency, nocturia, urgency, and urgency incontinence.

The severity of LUTS associated with BPH can be measured reliably, from the patient's perspective, with a validated questionnaire, such as the International Prostate Symptom Score (IPSS). IPSS is recommended by WHO as the symptom-scoring tool to be used for the baseline assessment of symptom severity in men presenting with LUTS. ${ }^{5}$ In the clinical setting, it can be used to assess the severity of symptoms in men with LUTS thus guiding mode of treatment. Uroflowmetry is indicated in patients with signs and symptoms suggestive of bladder outlet obstruction. It is one of the components of Pressure-flow Study. The pressure-flow study (PFS) is the reference standard for evaluating bladder outlet obstruction (BOO) due to BPH in male patients. ${ }^{6}$ However, PFS is an invasive procedure that cannot be performed in all cases. The reported side effects include hematuria, urinary tract infection, and difficulty in urination. ${ }^{7}$ The urinary flow rate is the strength or intensity of the urinary stream over time determined by measurement of the voided volume and the voiding or micturition time. Units are expressed as $\mathrm{ml} / \mathrm{sec}$. The most commonly reported measure is the peak or maximal urinary flow rate (Qmax). A peak flow rate of $\langle 15 \mathrm{ml} / \mathrm{sec}$ has been interpreted to be suggestive of BOO. This parameter, however, is nonspecific as Qmax decreases with advancing age.

\section{Rationale}

The symptomatology of LUTS is poorly correlated with the degree of BOO, of which the likelihood is still best predicted by electronic uroflowmetry. ${ }^{8-14}$ Studies conducted by various authors such as Singla et al., Itoh $\mathrm{H}$ et al., and Rosette et al., have shown a positive correlation between LUTS and uroflometry ${ }^{15-17}$. Whereas, Barry MJ et al. have found a weakly positive correlation between Qmax and symptom score ${ }^{18}$ and no significant 
correlation between Qavg and LUTS was found by Berry SJ et al. ${ }^{1}$ Moreover, a negative correlation between prostate size and LUTS has been found in a study conducted by Singla $e t$ al. ${ }^{15}$ So, we planned to do this study to see if there actually is a positive correlation between LUTS and Uroflowmetry and LUTS and prostate size, in the people of eastern Nepal. The findings of research may also guide us in measuring the symptoms severity, mode of management and to evaluate efficacy of treatment.

\section{Symptom Scores}

The IPSS, initially named the American Urological Association (AUA) Symptom Score, has been developed and established by the committee of the AUA. ${ }^{19}$ AUA in 1992 developed the symptom index specifically as an outcome measure in study of different BPH therapies. ${ }^{15}$ Presently IPSS has been the most widely used assessment tool in BPH. Validated translations of IPSS have been made in multiple languages making it applicable virtually worldwide. Finally, IPSS results do not appear to be substantially influenced by non clinical factors including race and ethnicity. ${ }^{20}$ In IPSS, each question evaluating a combination of urinary storage and voiding symptoms, allows the patient to choose one of the points ranging from 0-5 indicating increasing severity. The total score ranges from 0 to 35 (asymptomatic to very symptomatic).Patients scoring less than 8 points are classified as mildly symptomatic, those scoring 8-19 points are moderately symptomatic and those scoring 20-35 points are severely symptomatic. The IPSS, however, is not specific for BPH. Other urological conditions like urinary tract infections, chronic prostatitis, urethral stricture, neurogenic bladder, and congestive cardiac failure may give rise to LUTS. Thus it should never be used as a tool to screen for or diagnose $\mathrm{BPH}^{21}$

\section{Uroflowmetry}

It is a test to determine the flow rate of urine using an electronic flow meter. The purpose of the uroflow examination is to record one or more micturition that are representative of the patients' usual voiding pattern. The patient is instructed not to urinate for couple of hours and to drink plenty of fluids, until he has an urge to micturate. To perform this test, patient urinates into a special toilet equipped with an uroflowmeter. It is important that the patient remains still while urinating to help ensure accuracy, and that he urinates normally without exerting strain to empty his bladder or attempt to retard his urine flow. The rate of urine flow is calculated as milliliter of urine passed per second $(\mathrm{ml} / \mathrm{s})$. At its peak, the flow rate measurement is recorded and referred to as Qmax. Qave is the average amount of urine voided in a unit time and it is expressed as $\mathrm{ml} / \mathrm{s}$. Hesitancy time is the time taken to initiate the flow of urine after patient makes an effort to micturate. It is expressed in seconds. Total volume and voiding time are other parameters that can be determined with uroflowmetry. Single episode office uroflowmetry may not be sufficiently reliable for the determination of BOO due to $\mathrm{BPH}$, because many patients are unable to relax and void in the normal fashion while at the clinic. Moreover, since variability between consecutive flow measurements and circadian changes may be found in various voiding parameters, and specifically in Qmax, any decision based on a single flow measurement is questionable (Golomb J et al 1992).

In a study on "experience with uroflowmetry in evaluation of lower urinary tract symptoms in patients with benign prostatic hyperplasia" conducted by Singla et al., it was found that there was a positive correlation between peak flow rate as was measured by uroflowmetry and lower urinary tract symptom severity. ${ }^{15}$

A similar study on " significant relationship of time- dependent uroflowmetric parameters to lower urinary tract symptoms as measured by the IPSS " conducted by Itoh H. et al., demonstrated that age , voiding time and average and maximum flow rates correlates significantly with symptom scores. In particular, relatively strong relationships were found between average flow rate and scores of intermittency, weak stream and total and voiding symptom scores. ${ }^{16}$

In a prospective study on "Role of Uroflowmetry in the Assesment of lower urinary tract Obstruction in adult males" by Ismail Shoukry et al., conducted on 173 prostatic patients which was done to determine the respective value of symptoms, uroflowmetry, endoscopic and radiological findings in the assessment of the degree of urinary obstruction, it was confirmed that accurate uroflowmetry is a valuable tool in the assessment of lower urinary tract obstruction in males. Maximum urinary flow rate reflects bladder outlet obstruction better than other parameters ${ }^{22}$

In a study on "Change in urinary symptoms and quality of life in men with benign prostatic hyperplasia after transurethral resection of prostate" by Chalise PR et al., it was concluded that prostate volume had no correlation with age, symptom score, and quality of life score. So prostatic size should not be an only and important consideration; moreover, we should assess the impact of symptoms while treating the cases. ${ }^{22}$

\section{Aims And Objectives}




\section{Primary objective:}

hyperplasia.

To study the correlation between IPSS and uroflowmetry in patients with symptomatic benign prostatic

\section{Secondary objectives:}

1. To determine the age group that is most affected by BPH.

2. To correlate the prostatic size with symptom severity.

3. To correlate Post Voiding Residual Urine with symptom severity.

Study design: Prospective study

\section{Materials And Methods}

Duration of study: 1 yrs from JUNE 2015 to MAY 2016.

Setting: Urology OPD, Department of Surgery, Division of Urology ,B.P.K.I.H.S, Dharan.

Sampling technique: Consecutive patients

Sample size: 100 patients

Ethical clearance:

Ethical clearance letter was obtained from the Institutional Ethical Review Board (IERB).

Inclusion criteria:

Patients of BPH presenting with Lower urinary tract symptoms with IPSS $>7$ in the age group of 50 and above.

\section{Exclusion criteria:}

1. Patients that had indwelling Foley's catheter.

2. Patients who had undergone prior urinary tract or pelvic surgeries.

3. Patients who had past history of prostatic surgery, prostatic carcinoma, urethral stricture, vesicle calculus or neurogenic bladder.

4. Patients who had systemic disorders that can influence bladder function such as neurological disorders.

5. Patients whose voided urine volume was less than $150 \mathrm{ml}$.

6. Patients that did not give consent.

\section{Methodology}

All patients of BPH visiting urology OPD, fulfilling inclusion criteria, were included in the study. These patients were evaluated by using IPSS questionnaire with the assistance of the researchers, and then uroflowmetry was performed on them. The patients were asked to void when they felt a 'normal' desire to void, into a special urinal connected to a measuring instrument and adequate privacy was provided to them. The uroflowmetry machine gave the result as peak flow rate, voiding time and voiding volume, among other parameters. The test involved normal urination, hence the patient did not experience any discomfort. The results of uroflowmetry obtained from these patients were also recorded in the preformed proforma.

\section{Statistical Analysis}

The data was entered, cleaned and coded in Microsoft excel. The data was then exported and analysed through Statistical Package for the Social Sciences (SPSS), version 16.

\section{Results}

The mean age of the patients was found to be 65.2 years. A majority of the patients $(47.5 \%)$ were in the age group of 60-69 years (Fig 1). As per IPSS scoring, out of 100 patients, 75 had moderate symptoms while 25 had severe symptoms. The mean prostatic size was 39.95, with a range of 22-87. When the patients were divided as per their symptom severity scores, the mean prostatic size in patients with moderate symptoms was 34.65 , and that in patients with severe symptoms, it was 55.85. The overall correlation co-efficient of IPSS with prostatic size was found to be 0.533 (Table 1). The mean PVRU in patients was 111.84, with a range of 10-504 (Table 2). In our study, the mean value of peak flow rate was found to be $31.03 \mathrm{ml} / \mathrm{sec}$, with a minimum recording of $9 \mathrm{ml} / \mathrm{sec}$ and a maximum recording of $73 \mathrm{ml} / \mathrm{sec}$ (Table 3) The mean average flow rate was found to be 6.242 , with a minimum recording of 0.6 and a maximum recording of $17 \mathrm{ml} / \mathrm{sec}$ (Table 4). In our study, the voided volume was found to have an insignificant relationship with symptom severity (Table-5). 


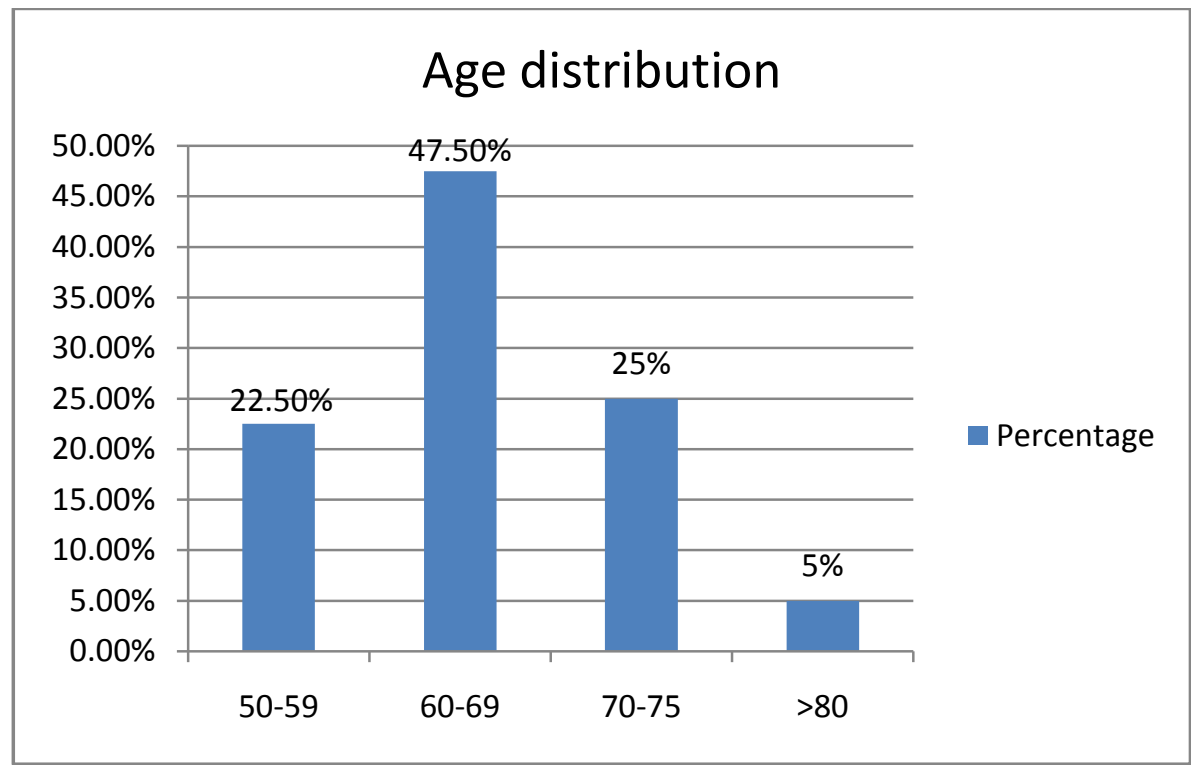

Figure 1- Age distribution of patients with symptomatic BPH

\begin{tabular}{|l|l|l|}
\hline Prostate size $(\mathrm{cc})$ & Mean $(\mathrm{SD})$ & $39.95(13.837)$ \\
\cline { 2 - 3 } & Range & $22-87$ \\
\cline { 2 - 3 } & Correlation co-efficient with IPSS & 0.533 \\
\cline { 2 - 3 } & P value & $-0.001(\mathrm{HS})$ \\
\hline
\end{tabular}

\section{Table 1- Prostate size}

\begin{tabular}{|l|l|l|}
\hline PVRU (ml) & Mean (SD) & $111.84(126.5050)$ \\
\cline { 2 - 3 } & Range & $10-504 \mathrm{cc}$ \\
\cline { 2 - 3 } & Co- relation co-efficient (r) with IPSS & 0.451 \\
\cline { 2 - 3 } & P value & $.001(\mathrm{HS})$ \\
\hline
\end{tabular}

Table 2- Post Voiding Residual Volume

\begin{tabular}{|l|l|l|}
\hline Peak flow rate $(\mathrm{ml} / \mathrm{sec})$ & Mean $(\mathrm{SD})$ & $31.03(14.919)$ \\
\cline { 2 - 3 } & Range & $9-73$ \\
\cline { 2 - 3 } & $\begin{array}{l}\text { Correlation co-efficient (r) with } \\
\text { IPSS }\end{array}$ & -0.194 \\
\cline { 2 - 3 } & P value & $.331(\mathrm{NS})$ \\
\hline
\end{tabular}

Table 3- Peak flow Rate (Qmax)

\begin{tabular}{|l|l|l|}
\hline Average Flow rate (ml/sec) & Mean (SD) & $6.243(3.38)$ \\
\cline { 2 - 3 } & Range & $0.6-17$ \\
\cline { 2 - 3 } & $\begin{array}{l}\text { Correlation co-efficient (r) with } \\
\text { IPSS }\end{array}$ & -0.079 \\
\cline { 2 - 3 } & P value & $.639(\mathrm{NS})$ \\
\hline
\end{tabular}

Table 4- Average flow rate (Qavg)

\begin{tabular}{|l|l|l|}
\hline Voided volume (ml) & Mean (SD) & $380.60(150.639)$ \\
\cline { 2 - 3 } & Range & $181-866$ \\
\cline { 2 - 3 } & $\begin{array}{l}\text { Correlation co-efficient (r) with } \\
\text { IPSS }\end{array}$ & -0.031 \\
\cline { 2 - 3 } & P value & $0.086(\mathrm{NS})$ \\
\hline
\end{tabular}

Table -5 Voided volume

\section{Discussion}

This study, which was done on 100 patients, was designed to determine the relationship among the parameters of uroflowmetry and symptom severity. The mean age of the patients in this study was 65.2 years. Most of the patients (47.5\%) were in the age group of 60-69 years. Singla et al., in their study displayed almost similar results with patients who had mean age of 67.7 years. Similarly, Mebust et al., in their study reported patients with average age of 69 years. In our study, the mean prostatic size was $39.95 \mathrm{cc}$, with a range of 2287.In a similar study conducted on 354 patients by Vesely et al., the average prostate volume was found to be $40.1 \mathrm{cc}$. Dicuio et al., found average prostate volume to be $41 \mathrm{cc}$, in a study conducted on $25 \mathrm{men}$. In another study conducted by Chalise PR, Agrawal CS, the average volume of prostate was $46.1 \mathrm{cc}$. In our study, the mean 
prostatic size in patients with moderate symptoms was 34.65 , and that in patients with severe symptoms, it was 55.85. The overall correlation coefficient of IPSS with prostatic size was found to be 0.533 , a moderate positive correlation. According to a study conducted by Singla et al., the mean prostatic size in patients with moderate symptoms was 54.2, while in patients with severe symptoms it was 65 . However, the p-value in the study was found to be $>0.05$, which was not significant. In their study, the overall correlation coefficient of IPSS with prostatic size was found to be 0.24 . Hence, there was no correlation found between IPSS and prostatic size. Our results were not consistent with previous studies probably due to the fact that patients were uneducated and needed assistance of researchers to fill the questionnaire.

In our study, PVRU had a weakly positive correlation $(r=0.451)$ with severity of urinary symptoms. Consistent with our results, Singla et al., found that PVRU had a weakly positive correlation with severity symptoms.In our study, the mean value of Qmax was found to be 31.03, with a range of 9-73. The Qmax had a weakly positive correlation with symptom score. Similarly, Barry MJ et al., have reported weakly positive correlations between Qmax and symptom score. The mean Qavg in our study was found to be 6.242, with a range of 0.6-17 and on comparing the variables by using Student's T- test, the p-value was found to be 0.469, not significant. Hence, no significant correlation was found between symptom score and Qavg. A similar result was obtained by Barry MJ, Girman CJ. In our study, the voided volume was found to have an insignificant relationship with symptom severity.

\section{Conclusion}

Of the 100 patients that presented with BPH, most of the patients (47.5\%) were in the age group of 6069 years. It was found that prostate size had moderately positive correlation with LUTS while PVRU was found to have a weakly positive correlation with severity of urinary symptoms. Among the parameters which were obtained by uroflowmetry, Peak flow rate (Qmax) was found to be the most representative of the symptom severity of the patient. Average flow rate (Qavg) and voided volume showed no correlation with the symptoms of the patients. Through our study, we concluded that uroflowmetry is a valuable tool for the diagnosis of patients presenting with Lower Urinary Tract Symptoms. We can also assess the efficacy of our treatment by performing pre operative and post operative uroflowmetry.

\section{References}

[1]. Berry SJ, Coffey DS, Walsh PC, Ewing LL. The development of human benign prostatic hyperplasia with age. J Urol. 1984;132(3):474-9.

[2]. Thorpe A, Neal D. Benign prostatic hyperplasia. Lancet. 2003;361(9366):1359-67.

[3]. Guler C, Tuzel E, Dogantekin E, Kiziltepe G. Does sildenafil effect uroflowmetry values in men with lower urinary tract symptoms suggestive of benign prostatic enlargement? Urol. Int 2008;80(2):181-5.

[4]. Kaplan SA, Olsson CA, Te AE. The American Urological Association symptom score in the evaluation of men with lower urinary tract symptoms: at 2 years of followup, does it work? J Urol. 1996;155(6):1971-4.

[5]. Kaplan SA. Update on the american urological association guidelines for the treatment of benign prostatic hyperplasia. Rev Urol. 2006;8 Suppl 4:S10-7.

[6]. Abrams P. In support of pressure-flow studies for evaluating men with lower urinary tract symptoms. Urology. 1994;44(2):153-5.

[7]. Klingler HC, Madersbacher S, Djavan B, Schatzl G, Marberger M, Schmidbauer CP. Morbidity of the evaluation of the lower urinary tract with transurethral multichannel pressure-flow studies. J Urol. 1998;159(1):191-4.

[8]. Michel M, de la Rosette J. Medical treatment of lower urinary tract symptoms suggestive of benign prostatic hyperplasia. Eur Urol Suppl 2009;8:496-503.

[9]. McConnell JD,Roehrborn CG, Bautista OM et al. The long-term effect of doxazosin, finasteride and combination therapy on the clinical progression of benign prostatic hyperplasia. N Engl J Med 2003;349:2387-98.

[10]. Roehrborn CG, for the MTOPS Research Group. Baseline measures as predictors of clinical progression of benign prostatic hyperplasia. Eur Urol Suppl 2004; 3: 88.

[11]. Kalejaive O, Speakman MJ. Management of acute and chronic retention in men. Eur Urol Suppl 2009; 8: 523-9.

[12]. Sacks SH, Aparicio SA, Bevan A, Oliver DO, Will EJ, Davison AM. Late renal failure due to prostatic outflow obstruction: a preventable disease. BMJ 1989; 298: 156-9.

[13]. Abrams PH, Royalance J, Feneley RC. Excretion urography in the investigation of prostatism. Br J Urol 1976; 48: 681-4.

[14]. de Lacey G, Johnson S, Mee D. Prostatism: how useful is routine imaging of the urinary tract? Br Med J (Clin Res Ed) 1988; 296: 965-7.

[15]. Singla S, Garg R, Singla A, Sharma S, Singh J, Sethi P. Experience with uroflowmetry in evaluation of lower urinary tract symptoms in patients with benign prostatic hyperplasia.

[16]. Itoh H, Kojima M, Okihara K, Ukimura O,Ushijima S, Kawauchi A et al. Significant relationship of time- dependent uroflowmetric parameters to lower urinary tract symptoms as measured by the International Prostate Scoring System. Int J Urol. 2006 Aug;13(8):1058-65.

[17]. Rosette, Witjes WP, Debruyne FM, Kersten PL, Wijkstra H. Improved reliability of uroflowmetry investigation: results of a portable home based uroflowmetry study. British Journal Of Urology (1996),78,385-390.

[18]. Barry MJ, Fowler FJ, Jr., O'Leary MP, Bruskewitz RC, Holtgrewe HL, Mebust WK. Correlation of the American Urological Association symptom index with self-administered versions of the Madsen-Iversen, Boyarsky and Maine Medical Assessment Program symptom indexes. Measurement Committee of the American Urological Association. J Urol 1992;148(5):1558-63; discussion 64

[19]. Badia X, Rodriguez F, Carballido J, Garcia Losa M, Unda M, Dal-Re R, et al. Influence of sociodemographic and health status variables on the American Urological Association symptom scores in patients with lower urinary tract symptoms. Urology. 2001;57(1):71-7. 
[20]. Barry MJ, Fowler FJ, Jr., O'Leary MP, Bruskewitz RC, Holtgrewe HL, Mebust WK, et al. The American Urological Association symptom index for benign prostatic hyperplasia. The Measurement Committee of the American Urological Association. J Urol. 1992;148(5):1549-57; discussion 64.

[21]. Jorgensen JB, Jensen KM, Bille-brahe NE and Morgensen P. Uroflowmetry in asymptomatic elderly males. British Journal Of Urology (1986), 58, 390-395.

[22]. Chalise PR, Agrawal CS. Change in urinary symptoms and quality of life in men with benign prostatic hyperplasia after transurethral resection of prostate. Nepal Med Coll J. 2007 Dec;9(4):255-8 